\title{
Decomposition of 2-naphthalenesulfonate in electroplating solution by ozonation with UV radiation
}

\author{
Yi-Hung Chen ${ }^{\mathrm{a}}$, Ching-Yuan Chang ${ }^{\mathrm{a}, *}$, Shih-Fong Huang ${ }^{\mathrm{a}}$, Neng-Chou Shang ${ }^{\mathrm{a}}$, Chun-Yu Chiu ${ }^{\mathrm{b}}$, \\ Yue-Hwa Yu ${ }^{\mathrm{a}}$, Pen-Chi Chiang ${ }^{\mathrm{a}}$, Je-Lueng Shie ${ }^{\mathrm{c}}$, Chyow-San Chiou ${ }^{\mathrm{c}}$ \\ ${ }^{a}$ Graduate Institute of Environmental Engineering, National Taiwan University, Taipei 106, Taiwan \\ ${ }^{\mathrm{b}}$ Department of Environmental Engineering, Lan-Yang Institute of Technology, I-Lan 261, Taiwan \\ ${ }^{\mathrm{c}}$ Department of Environmental Engineering, National I-Lan University, I-Lan 261, Taiwan
}

Received 8 August 2004; received in revised form 21 October 2004; accepted 27 October 2004

Available online 9 December 2004

\begin{abstract}
This study investigates the ozonation of 2-naphthalenesulfonate (2-NS) combined with UV radiation in the electroplating solution. 2-NS is commonly used as a brightening and stabilization agent in the electroplating solution. Semibatch ozonation experiments were conducted under various reaction conditions to study the effects of ozone dosage and UV radiation on the oxidation of 2-NS. The concentrations of 2-NS were analyzed at specified time intervals to elucidate the decomposition of 2-NS. Total organic carbon (TOC) is chosen as a mineralization index of the ozonation of 2-NS. In addition, values of $\mathrm{pH}$ and oxidation reduction potential were continuously measured in the course of experiments. As a result, the nearly complete mineralization of 2-NS via the ozonation treatment can be achieved. The mineralization of 2-NS is found accelerated by the introduction of UV radiation and has a distinct relationship with the consumption of applied ozone. These results can provide useful information for the proper removal of 2-NS in the electroplating solution by the ozonation with UV radiation.
\end{abstract}

(C) 2004 Elsevier B.V. All rights reserved.

Keywords: Ozone; Ozonation; UV radiation; 2-Naphthalenesulfonate; Electroplating solution

\section{Introduction}

Discarded aged electroplating solution is one of the major wastewater sources in the printed wiring board (PWB) industry. The substrates (the major chemical species) of solution recipe are inorganics such as sulfuric acid, copper sulfate, hydrochloric acid, etc., while the minor substances are organics such as 2-naphthalenesulfonate (2-NS), which is commonly used as a brightening and stabilization agent [1]. Consequently, the characteristics of wasted electroplating solution exhibit high acidity $(\mathrm{pH}=0.18-0.42)$ and ionic strength. All of the above features make the solution hard to be treated by the conventional treatment processes $[1,2]$. The current major method used to treat the waste electroplating solution of PWB is chemical coagulation, which produces hazardous

\footnotetext{
* Corresponding author. Tel.: +88622363 8994; fax: +886223638994.

E-mail address: cychang3@ntu.edu.tw (C.-Y. Chang).
}

chemical sludge because of its high heavy metal content such as copper.

In Taiwan, the yield of the waste electroplating solution of PWB is approximately $1.23 \mathrm{~m}^{3} / \mathrm{s}$, resulting in about $2.1 \times 10^{7} \mathrm{~kg}$ waste and hazardous sludge per year with $78 \mathrm{wt} . \%$ water content [3]. Furthermore, in view of the resource recycling, the aged electroplating solution of PWB has high reclamation and recycling potentials with high copper concentration and electric conductivity. Note that the qualities of the organics in the electroplating solution become low and unreliable to the process after a certain period of time of operations of the electroplating and electrophoresis. For this reason, removal of the spent organic additives with the replacement by adding new additives is one of the key steps for the reutilization of process solution. Ozonation is an effective way to remove organics and reduce the total organic carbons (TOCs). The compounds may be attacked via two different reaction mechanisms: (1) the direct ozonation 


\begin{tabular}{|c|c|}
\hline \multicolumn{2}{|c|}{ Nomenclature } \\
\hline$C_{\mathrm{AGi}}$ & $\begin{array}{l}\text { gas concentration of ozone of inlet gas ( } \mathrm{mg} / \mathrm{L} \\
\text { or } \mathrm{M})\end{array}$ \\
\hline$C_{\mathrm{AGe}}$ & $\begin{array}{l}\text { gas concentration of ozone of discharged gas } \\
(\mathrm{mg} / \mathrm{L} \text { or } \mathrm{M})\end{array}$ \\
\hline$C_{\mathrm{AL}}$ & $\begin{array}{l}\text { concentration of ozone in bulk liquid }(\mathrm{mg} / \mathrm{L} \text { or } \\
\mathrm{M})\end{array}$ \\
\hline$C_{\mathrm{ALS}}$ & $\begin{array}{l}\text { dissolved ozone concentration of liquid at } \\
\text { gas-liquid interface }(\mathrm{M})\end{array}$ \\
\hline$C_{\mathrm{BL}}$ & $\begin{array}{l}\text { concentration of } 2-\mathrm{NS} \text { in bulk liquid }(\mathrm{mg} / \mathrm{L} \text { or } \\
\mathrm{M})\end{array}$ \\
\hline$C_{\mathrm{BL} 0}$ & $\begin{array}{l}\text { initial concentration of } 2-\mathrm{NS} \text { in bulk liquid } \\
(\mathrm{mg} / \mathrm{L} \text { or } \mathrm{M})\end{array}$ \\
\hline$C_{\mathrm{e}}$ & experimental data \\
\hline $\bar{C}_{\mathrm{e}}$ & average value of all experimental data \\
\hline$C_{\mathrm{p}}$ & predicted values \\
\hline$C_{\mathrm{TOC}}$ & $\begin{array}{l}\text { concentration of total organic carbon (TOC) } \\
(\mathrm{mg} / \mathrm{L} \text { or } \mathrm{M})\end{array}$ \\
\hline$C_{\mathrm{TOC}_{0}}$ & initial concentration of TOC $(\mathrm{mg} / \mathrm{L}$ or $\mathrm{M})$ \\
\hline$H_{\mathrm{A}}$ & $\begin{array}{l}\text { dimensionless Henry's constant of ozone } \\
\left(\mathrm{M} \mathrm{M}^{-1}\right)\end{array}$ \\
\hline$H_{\mathrm{e}}$ & $\begin{array}{l}\text { Henry's law constant of ozone, } p_{\mathrm{Ai}} / C_{\mathrm{ALS}} \\
(\operatorname{atmL} / \mathrm{mol})\end{array}$ \\
\hline$\left[I_{\mathrm{UV}}\right]$ & photon flux of UV entering the reactor $\left(\mathrm{W} / \mathrm{m}^{2}\right)$ \\
\hline$k_{\mathrm{B}}$ & $\begin{array}{l}\text { pseudo-first-order reaction rate constant of } 2- \\
\text { NS }\left(\min ^{-1}\right)\end{array}$ \\
\hline$m_{\mathrm{O}_{3} \mathrm{R}}$ & ozone consumption (mol) \\
\hline 2-NS & 2-naphthalenesulfonate \\
\hline ORP & oxidation reduction potential \\
\hline $\begin{array}{l}p_{\mathrm{Ai}} \\
O_{\mathrm{G}}\end{array}$ & $\begin{array}{l}\text { partial pressure of ozone of gas (atm) } \\
\text { gas flow rate (L/min) }\end{array}$ \\
\hline $\begin{array}{l}R^{2} \mathrm{G} \\
R^{2}\end{array}$ & $\begin{array}{l}\text { determination coefficient, } \\
{\left[\sum\left(C_{\mathrm{e}}-C_{\mathrm{p}}\right)^{2} / \sum\left(C_{\mathrm{e}}-\bar{C}_{\mathrm{e}}\right)^{2}\right]}\end{array}$ \\
\hline TOC & total organic carbon \\
\hline & volume of free space $(\mathrm{L})$ \\
\hline & volume of solution (L) \\
\hline$t$ & ozonation time (min) \\
\hline \multicolumn{2}{|c|}{ Greek symbol } \\
\hline$\eta_{\mathrm{TOC}}$ & $\begin{array}{l}\text { removal efficiency of TOC defined by Eq. (1) } \\
(\%)\end{array}$ \\
\hline
\end{tabular}

by the ozone molecule and (2) the radical oxidation by the highly oxidative free radicals such as hydroxyl free radicals, which are formed by the decomposition of ozone in the aqueous solution [4]. The radical oxidation is non-selective and vigorous.

Recently, Chen et al. [5] investigated the decomposition of 2-NS in the aqueous solution by ozonation with ultraviolet (UV) radiation. Their results indicated that the combined process of ozonation with UV radiation is an effective way for the removal of 2-NS in the aqueous solu- tion. However, the information about the ozonation of 2NS in the electroplating solution, which has distinct properties from the aqueous solution, is still scarce but desirable for evaluating the practicability of removal of 2NS via ozonation treatment. Thus, the aim of the present study is to employ ozonation combined with UV radiation to eliminate 2-NS in the electroplating solution. The purpose of introducing UV radiation in the ozonation processes is to enhance the ozone decomposition yielding more free radicals for achieving a higher ozonation extent $[6,7]$.

Semibatch ozonation experiments are proceeded under various reaction conditions. The decomposition of 2-NS accompanies with the variations of TOC, gas and liquid ozone concentrations and oxidation reduction potential (ORP). The results obtained can provide useful information about the proper application of the process for the removal of 2 NS via ozonation with UV radiation in the electroplating solution.

\section{Materials and methods}

\subsection{Chemicals}

The substrate recipe of the electroplating solution is: $\quad\left[\mathrm{CuSO}_{4} \cdot 5 \mathrm{H}_{2} \mathrm{O}\right]=200 \mathrm{~g} / \mathrm{L}, \quad\left[\mathrm{H}_{2} \mathrm{SO}_{4}\right]=60 \mathrm{~g} / \mathrm{L}, \quad$ and $\left[\mathrm{Cl}^{-}\right]=0.03 \mathrm{~g} / \mathrm{L}$. The concentration of target organic compound of $2-\mathrm{NS}$ is $200 \mathrm{mg} / \mathrm{L}$ according to the prescription of electroplating solution [1]. The 2-NS with chemical formula as $\mathrm{C}_{10} \mathrm{H}_{7} \mathrm{SO}_{3} \mathrm{Na}$, which was purchased from Aldrich (Milwankee, WI, USA) and used without any further purification, has molecular weight of 230.22. The molecular structure of 2-NS is shown in Fig. 1. All experimental solutions were prepared with deionized water without other buffers. The initial values of $\mathrm{pH}$ and TOC of experimental solution are about 0.25 and $104 \mathrm{mg} / \mathrm{L}$, respectively. The dimensionless Henry's law constant $\left(H_{\mathrm{A}}\right)$ of ozone in the electroplating solution was determined as 4.18 [8]. Accordingly, the dimensional Henry's law constant of ozone $\left(H_{\mathrm{e}}\right)$ defined by $p_{\mathrm{Ai}}=H_{\mathrm{e}} C_{\mathrm{ALS}}$ is $102.1 \mathrm{~atm} \mathrm{~L} / \mathrm{mol}$.

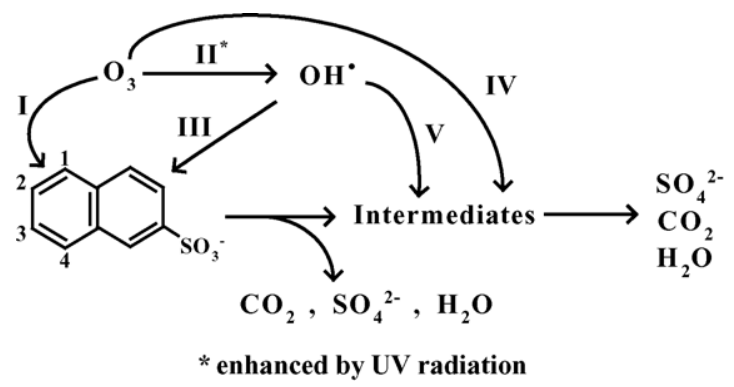

Fig. 1. The molecular structure and simplified scheme of the decomposition pathways of the ozonation of 2-naphthalenesulfonate (2-NS) with UV radiation. 


\subsection{Instrumentation}

The airtight reactor of inside diameter of $17.2 \mathrm{~cm}$ was made of Pyrex glass with an effective volume of $5.5 \mathrm{~L}$, and equipped with water jacket to maintain a constant solution temperature at $25^{\circ} \mathrm{C}$ in all experiments. The design of reactor was based on the criteria of the shape factors of a standard six-blade turbine [9]. The gas diffuser in cylindrical shape with pore size of $10 \mu \mathrm{m}$ was located at the bottom of reactor. Two quartz tubes of outside diameter of $3.8 \mathrm{~cm}$ installed symmetrically inside the reactor were used to house the UV lamps. The low-pressure mercury lamps emitted principally at $254 \mathrm{~nm}$ supplied the UV radiation. The radiation intensity was measured by a digital radiometer (Ultra-Violet Products (UVP), Upland, CA, USA) with a model UVP-25 radiation sensor. About 3.705 L solution was used in each experiment, while the total sampling volume was within $5 \%$ of solution. The stirred speed was as high as $800 \mathrm{rpm}$ to ensure the complete mixing of liquid and gas phases according to previous tests $[10,11]$. The generation of ozone gas was controlled by the power input of ozone generator (model SG-01A, Sumitomo, Tokyo, Japan) with constant gauge pressure $(0.968 \mathrm{~atm})$. The ozone generator used in this study employed two steel plate electrodes and ceramic dielectric. Ozone-containing gas generated by pure oxygen was introduced into the reactor with a gas flow rate of $1.94 \mathrm{~L} / \mathrm{min}$. A circulation pump was used to transport the liquid from the reactor to the sensors of monitors with a flow rate of $0.18 \mathrm{~L} / \mathrm{min}$, and to re-flow it back during the ozonation.

The concentrations of 2-NS $\left(C_{\mathrm{BL}}\right)$ were analyzed using high-performance liquid chromatography (HPLC) system with column of $250 \mathrm{~mm} \times 4.6 \mathrm{~mm}$ of model BDS C18 $(5 \mu \mathrm{m})$ (Thermo Hypersil-keystone, Bellfonte, PA, USA), and UV-vis detector (model 1706, Bio-Rad, Hercules, CA, USA) at $254 \mathrm{~nm}$. The ratio of water: $\mathrm{CH}_{3} \mathrm{CN}$ of composition of effluent with flow rate of $1.0 \mathrm{~mL} / \mathrm{min}$ was $83: 17$. The injection volume of analytic solution was $20 \mu \mathrm{L}$. The TOC concentrations $\left(C_{\mathrm{TOC}}\right)$ of samples were analyzed by a TOC analyzer (model 700, OI Corporation, Texas, USA). The instrument applies the UV-persulfate technique to convert the organic carbon for the subsequent analysis by an infrared carbon dioxide analyzer calibrated with the potassium hydrogen phthalate standard. The $\mathrm{pH}$ (model 300T, Suntex, Taipei, Taiwan) and ORP (model 900C, Apogee, Taipei, Taiwan) meters with sensors were used to measure the values of $\mathrm{pH}$ and ORP of solution. All fittings, tubings and bottles were made of stainless steel, teflon or glass. The experimental apparatus employed in this work is shown in Fig. 2.

\subsection{Experimental procedures}

The semibatch experiments of ozonation of 2-NS were performed to examine the variations of $C_{\mathrm{BL}}, C_{\mathrm{TOC}}, \mathrm{pH}$, and ORP. Before starting the ozonation experiments, the ozone-containing gas was bypassed to the photometric analyzer (model SOZ-6004, Seki, Tokyo, Japan) to assure the stability and ozone concentration. A part of gas stream at the preset flow rate was directed into the reactor when the ozonation system was ready to start. In addition, the concentrations of inlet $\left(C_{\mathrm{AGi}}\right)$ and discharged $\left(C_{\mathrm{AGe}}\right)$ gas ozone were measured. Liquid samples were drawn out from the reactor at desired time intervals in the course of ozonation of 2-NS. The photon flux of UV, $\left[I_{U V}\right]$ entering the reactor with value of $60.35 \mathrm{~W} / \mathrm{m}^{2}$ was employed to test the effect of UV radiation on the ozonation.

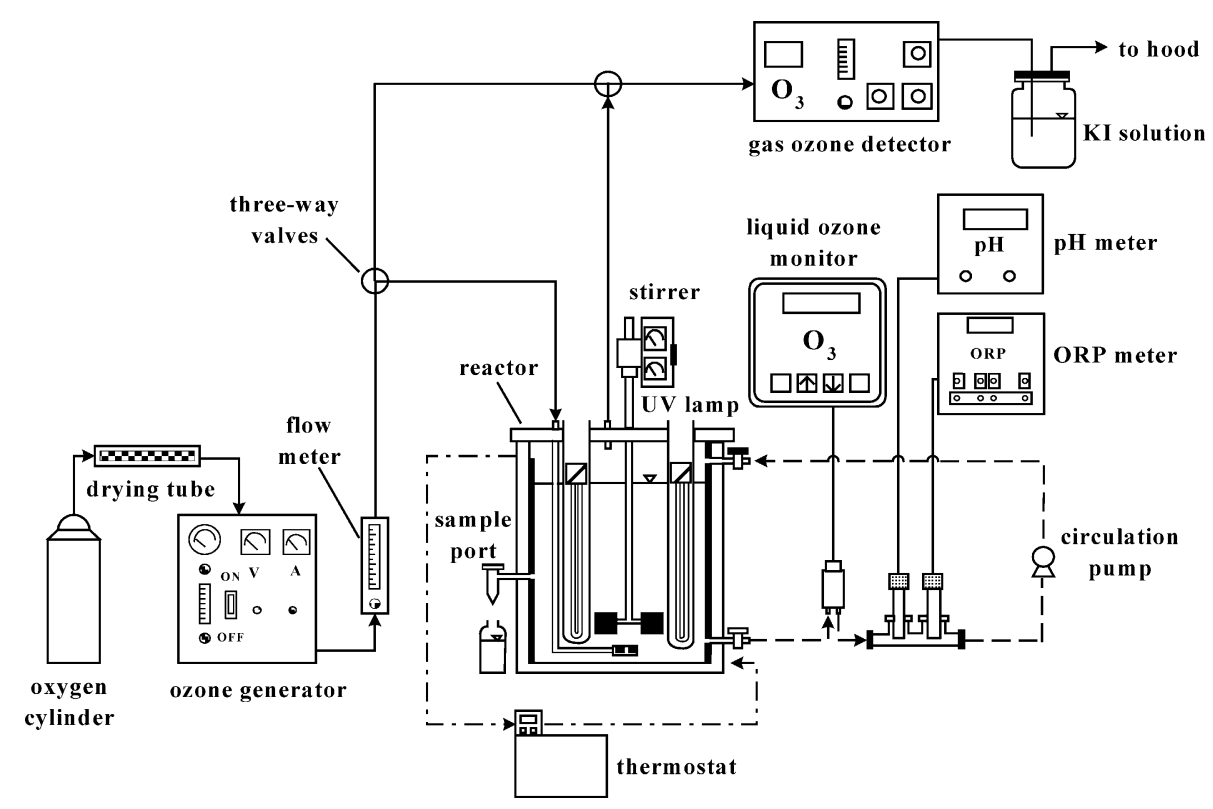

Fig. 2. The experimental apparatus sketch: (-) ozone gas stream, (--) experimental solution, and (---) isothermal water. 


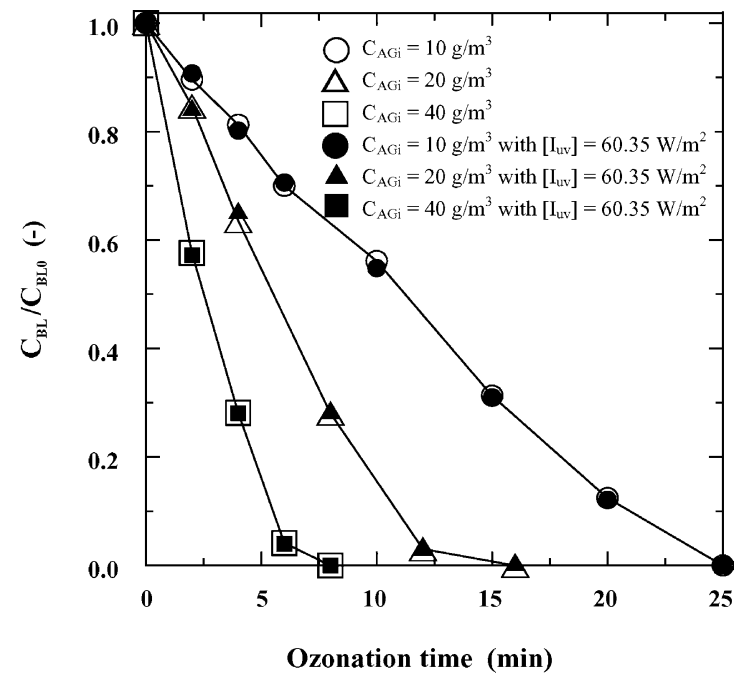

Fig. 3. Variation of $C_{\mathrm{BL}} / C_{\mathrm{BL}_{0}}$ with time for the ozonation of 2-NS in semibatch system. $C_{\mathrm{BL}}=C_{\mathrm{BL}_{0}}$ at $t=0$.

\section{Results and discussion}

\subsection{Decomposition of 2-NS during ozonation with UV radiation}

The time variations of the decomposition of 2-NS via the ozonations with and without UV radiation are shown in Fig. 3. The effect of the ozone concentration of feed gas on the decomposition of 2-NS is remarkable. The time required for the complete decomposition of 2-NS with $C_{\mathrm{AGi}}=40 \mathrm{mg} / \mathrm{L}$ is about one-third and half of those with $C_{\mathrm{AGi}}=10$ and $20 \mathrm{mg} / \mathrm{L}$, respectively. However, comparing the results of the cases with and without UV radiation indicates that the UV radiation affects the decomposition extent of 2-NS slightly.

In order to illustrate the possible roles of $\mathrm{O}_{3}$ and UV radiation on attacking the 2-NS and its intermediates, a simplified scheme of the decomposition pathways of 2-NS via the ozonation with UV radiation is proposed as shown in Fig. 1. The major contribution of UV is to generate $\mathrm{OH}^{\bullet}$ via reaction II. This can enhance the radical reaction of hydroxyl free radicals with 2-NS noted as reaction III, which is more vigorous than the direct reaction of $\mathrm{O}_{3}$ with 2-NS via reaction I. However, the decrease of dissolved ozone concentration then decreases the extent of reaction I. As the result, the overall decomposition extent of 2-NS in ozonation is only slightly accelerated by the UV radiation. Further, the pseudo-first-order kinetics for the elimination of 2-NS, $C_{\mathrm{BL}} / C_{\mathrm{BL} 0}=\exp ^{-k_{\mathrm{B}} t}$, can be obtained from Fig. 3 with $k_{\mathrm{B}}$ $\left(\mathrm{min}^{-1}\right)=0.0107 \pm 0.0042 C_{\mathrm{AGi}}$ for a $95 \%$ confidence interval, where $C_{\mathrm{AGi}}$ is in $\mathrm{mg} / \mathrm{L}$.

The decomposition of 2-NS accompanies a diminution of TOCs. The removal efficiencies of TOCs $\left(\eta_{\text {TOC }}\right)$ defined by Eq. (1) at time about 8-25 min, for the complete elimination of 2-NS are between 1 and $4 \%$ as shown in Fig. 4. The intermediates produced from the decomposi-

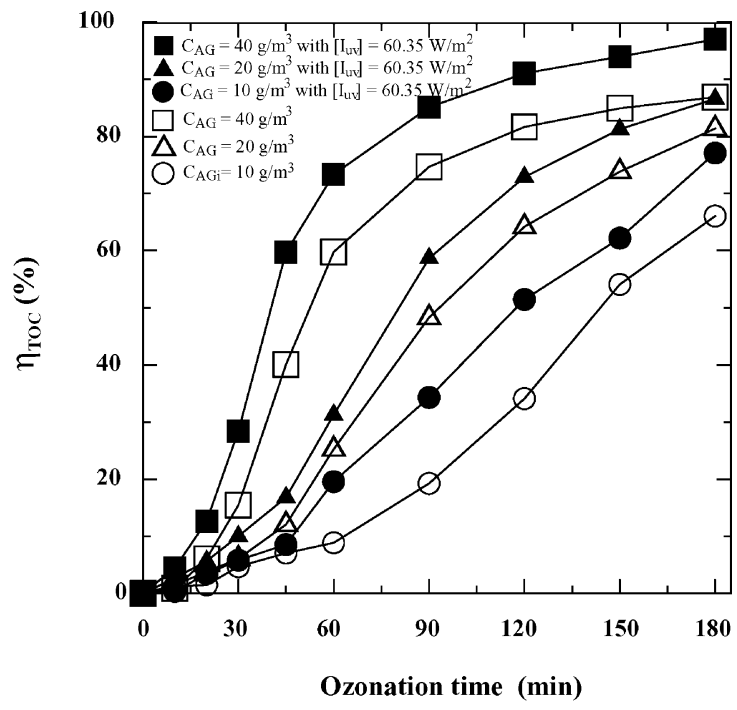

Fig. 4. Variation of $\eta_{\mathrm{TOC}}$ with time for the ozonation of 2-NS in semibatch system.

tion of 2-NS contribute over $96 \%$ TOC relative to the initial value.

$\eta_{\mathrm{TOC}}=\frac{C_{\mathrm{TOC}_{0}}-C_{\mathrm{TOC}}}{C_{\mathrm{TOC}_{0}}}$

where $C_{\mathrm{TOC}_{0}}$ and $C_{\mathrm{TOC}}$ are values of $C_{\mathrm{TOC}}$ at $t=0$ and $t$, respectively. The decrease of decomposition extent of 2-NS with ozonation time also counts for the generation of byproducts, which are also competitors for oxidation. The initial attacks of ozone on 2-NS may be proceeded via (1) an ozone dipolar cycloaddition on the 1,2 bond or (2) an electrophilic substitution of ozone on carbon 1 [5].

\subsection{Variations of removal efficiency of TOC and ozone concentration}

Fig. 4 shows the variation of removal efficiency of TOC $\left(\eta_{\text {TOC }}\right)$ under various experimental conditions. The value of $\eta_{\text {TOC }}$ increases with the ozonation time continuously. Apparently, the $C_{\mathrm{AGi}}$ significantly contributes the mineralization extent of 2-NS for both sole $\mathrm{O}_{3}$ and $\mathrm{O}_{3} / \mathrm{UV}$ systems. Moreover, the UV radiation in the ozonation of 2-NS also improves the removal of TOC. The $\mathrm{OH}^{\bullet}$ induced by the presence of UV radiation proceeds with higher $\eta_{\mathrm{TOC}}$ via the reaction noted as reaction $\mathrm{V}[12,13]$. Limiting values of $\eta_{\mathrm{TOC}}$ seem to appear for the sole ozonation of intermediates. The lower value of $\mathrm{d} \eta_{\text {TOC }} / \mathrm{d} t$ in the early stage of ozonation is due to the cause that ozone is first consumed for the opening of benzene rings and the oxidation of the sulfonic substituent, thus accompanying with the low diminution of TOCs. In addition, the lower value of $\mathrm{d} \eta_{\mathrm{TOC}} / \mathrm{d} t$ in the later ozonation stage (higher $\eta_{\mathrm{TOC}}$ ) is caused by the ozonation of resistant intermediates such as oxalic acid, phthalic acid, and formic acid, which have low reactivity towards ozone molecules $[14,15]$. 
Note that the cause for the apparent contribution of UV radiation on the mineralization of 2-NS during ozonation is attributed to the vigorous attack of hydroxyl radicals, for which the generation is enhanced by the UV radiation, on the intermediates that are more resistant to ozone than hydroxyl radicals. On the other hand, the insignificant effect of UV radiation on the decomposition of 2-NS is due to the high reactivity of 2-NS toward ozone. Similar phenomena were also observed during the ozonation of 2-NS in the aqueous solution [5]. Furthermore, the decomposition rates of 2-NS and TOC via sole ozonation in the electroplating solution seems to be faster in comparison with those in the aqueous solution. It may be caused by the catalytic effect of copper ions in the electroplating solution [16,17]. On the other hand, the enhancement of UV radiation on the mineralization of 2-NS during ozonation in the electroplating solution is weaker than that in the aqueous solution because of the lower transmission of UV radiation in the electroplating solution. In addition, the $\mathrm{pH}$ value of the electroplating solution is about 0.25 . The variation of $\mathrm{pH}$ during the ozonation experiments was found to be very slight due to the high acid concentration.

Moreover, the variations of dimensionless liquid $\left(C_{\mathrm{AL}} /\left(C_{\mathrm{AGi}} / H_{\mathrm{A}}\right)\right)$ and gas $\left(C_{\mathrm{AGe}} / C_{\mathrm{AGi}}\right)$ ozone concentrations with $\eta_{\mathrm{TOC}}$ for various cases are shown in Fig. 5 . In the first stage (with $\eta_{\mathrm{TOC}} \leq 5 \%$ ), the $C_{\mathrm{AL}}$ remains nearly undetectable (Fig. 5a). In this regime, the rate of ozonation reaction is very fast so that the ozone transferred from the gas phase is immediately consumed in the solution. Then the dissolved ozone starts to appear with $C_{\mathrm{AL}} /\left(C_{\mathrm{AGi}} / H_{\mathrm{A}}\right)$ having a value of about 0.11 in the regime with $34 \% \geq \eta_{\mathrm{TOC}}>5 \%$. Later, the $C_{\mathrm{AL}}$ gradually increases with $\eta_{\mathrm{TOC}}$ when $\eta_{\mathrm{TOC}}>34 \%$. The accumulation of dissolved ozone is attributed to the case that the consumption rate of dissolved ozone is lower than the gas-liquid mass transfer rate of ozone due to the lower reactivities of the refractory intermediates in the reacted solution. The variation of $C_{\mathrm{AL}}$ with $\eta_{\mathrm{TOC}}$ seems to be only slightly dependent on $C_{\mathrm{AGi}}$. Obviously, the $C_{\mathrm{AL}}$ has the smaller value in the case of $\mathrm{O}_{3} / \mathrm{UV}$ than that of sole $\mathrm{O}_{3}$. Fig. 5b shows that the $C_{\mathrm{AGe}} / C_{\mathrm{AGi}}$ increases rapidly in the beginning and has a value of $0.36-0.56$ when $\eta_{\mathrm{TOC}} \leq 34 \%$. The $C_{\mathrm{AGe}}$ apparently further increases with $\eta_{\text {TOC }}$ corresponding to the increase of $C_{\mathrm{AL}}$ as $\eta_{\mathrm{TOC}}>34 \%$.

\subsection{Removal of TOC associated with ozone consumption and ORP}

In addition, the relation between $\eta_{\text {TOC }}$ and the ozone consumption per mol 2-NS, $m_{\mathrm{O}_{3} \mathrm{R}} /\left(C_{\mathrm{BL}_{0}} V_{\mathrm{L}}\right)\left(\mathrm{mol} \mathrm{mol}^{-1}\right)$, is illustrated in Fig. 6. The ozone consumption $\left(m_{\mathrm{O}_{3} \mathrm{R}}\right)$ is calculated by Eq. (2), where $V_{\mathrm{L}}$ and $V_{\mathrm{F}}$ are the volumes of solution and free space in the reactor, respectively.

$m_{\mathrm{O}_{3} \mathrm{R}}=\int_{0}^{t} Q_{\mathrm{G}}\left(C_{\mathrm{AGi}}-C_{\mathrm{AGe}}\right) \mathrm{d} t-C_{\mathrm{AL}} V_{\mathrm{L}}-C_{\mathrm{AGe}} V_{\mathrm{F}}$
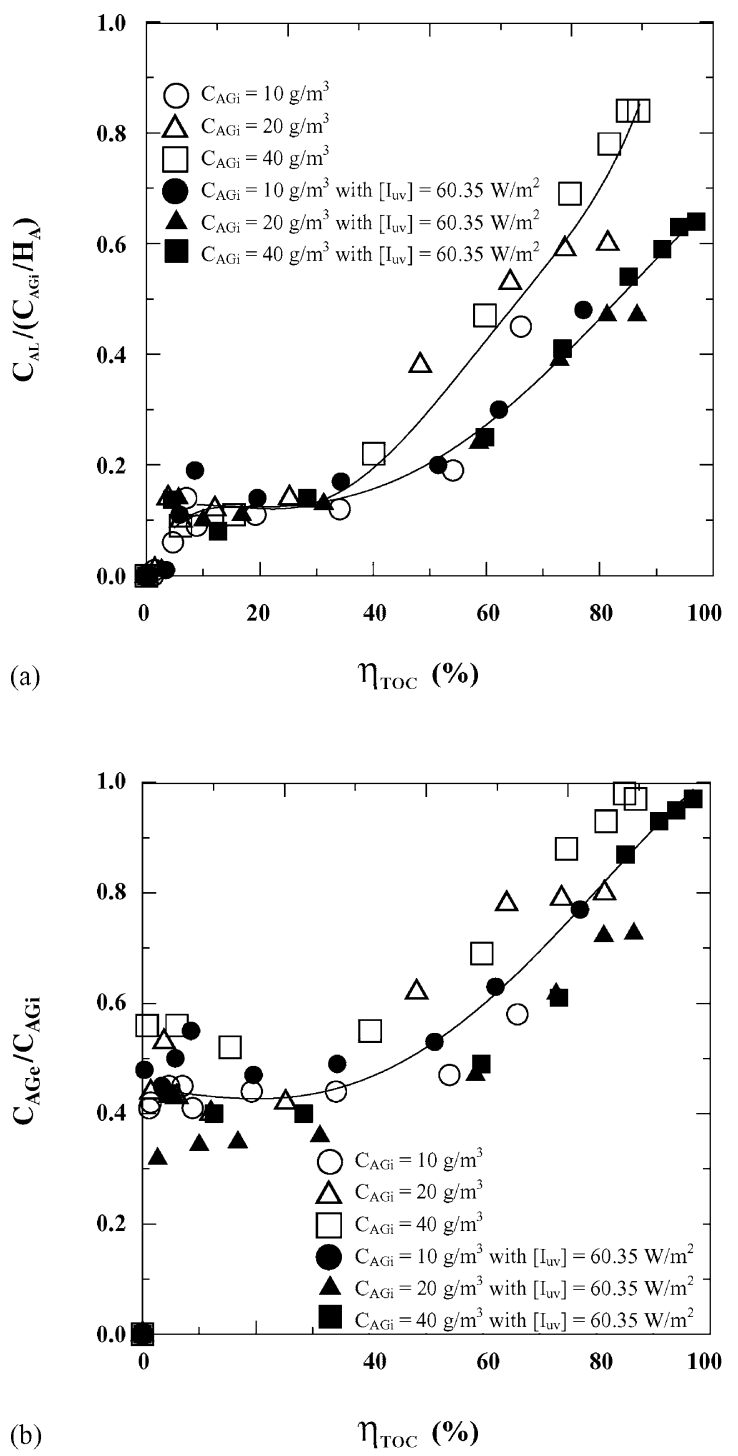

Fig. 5. $C_{\mathrm{AL}} /\left(C_{\mathrm{AGi}} / H_{\mathrm{A}}\right)$ and $C_{\mathrm{AGe}} / C_{\mathrm{AGi}}$ vs. $\eta_{\mathrm{TOC}}$ for the ozonation of 2-NS in semibatch system. Line: average and smooth curve of experimental data. (a) $C_{\mathrm{AL}} /\left(C_{\mathrm{AGi}} / H_{\mathrm{A}}\right)$; (b) $C_{\mathrm{AGe}} / C_{\mathrm{AGi}}$.

As a result, $\eta_{\mathrm{TOC}}$ increases with $m_{\mathrm{O}_{3} \mathrm{R}} /\left(C_{\mathrm{BL}_{0}} V_{\mathrm{L}}\right)$ apparently and agreeably in all cases examined, indicating a high correlation between the mineralization of 2-NS and the ozone consumption. It reveals that the value of ratio of $\eta_{\mathrm{TOC}} /\left(m_{\mathrm{O}_{3} \mathrm{R}} /\left(C_{\mathrm{BL}_{0}} V_{\mathrm{L}}\right)\right)$ is about $4.3 \%$ during the ozonation treatments of 2-NS. The $\eta_{\text {TOC }}$ approaches to $100 \%$, which stands for the nearly complete mineralization of 2-NS, as the value of $m_{\mathrm{O}_{3} \mathrm{R}} /\left(C_{\mathrm{BL}_{0}} V_{\mathrm{L}}\right)$ is greater than 23. It is worth noting that the higher mineralization extent of 2-NS in the $\mathrm{O}_{3} / \mathrm{UV}$ treatment is resulted from the greater consumption efficiency of applied ozone.

Fig. 7 presents the variation of ORP of liquid with $\eta_{\text {TOC. }}$. The value of ORP can be used as a supplementary ozonation index of ozonation system $[5,18]$. The experimental ORP data of the present study were further used to plot the average and smooth curve in Fig. 7, which shows the distinct 


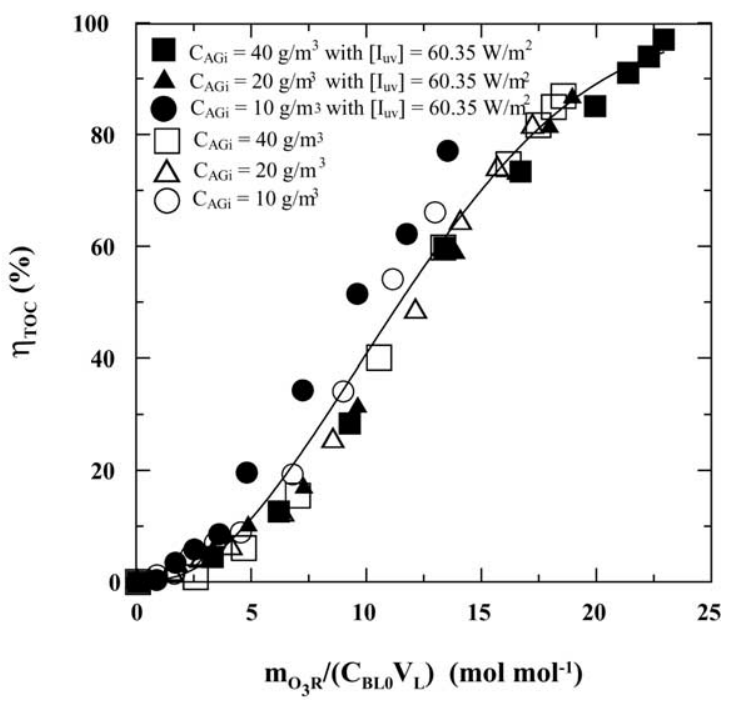

Fig. 6. $\eta_{\mathrm{TOC}}$ vs. $m_{\mathrm{O}_{3} \mathrm{R}} /\left(C_{\mathrm{BL}_{0}} V_{\mathrm{L}}\right)$ for the ozonation of 2-NS in semibatch system. Line: average and smooth curve of experimental data with $R^{2}=0.980$.

variation of ORP with $\eta_{\mathrm{TOC}}$. The value of ORP reveals a slight variation in the initial period while a significant increase in the later period for $10 \%<\eta_{\mathrm{TOC}}<30 \%$. The initial ORP value of the electroplating solution before ozonation is $426 \mathrm{mV}$. For $\eta_{\mathrm{TOC}} \leq 10 \%$, the values of ORP are between 700 and $785 \mathrm{mV}$. In this stage, the organics of TOCs in the solution are predominant for controlling the ORP of system with small variation. As the concentration of TOCs $\left(C_{\mathrm{TOC}}\right)$ decreases below $93.6 \mathrm{mg} / \mathrm{L}\left(\eta_{\mathrm{TOC}}>10 \%\right)$, the ORP starts to increase with $\eta_{\mathrm{TOC}}$ as shown in Fig. 7. This regime may be called the transient stage. As the $\eta_{\text {TOC }}$ is close to $50 \%$, the value of ORP of system approaches to that of organic-free solution of about $1360 \mathrm{mV}$. Thus, ORP is a useful index associated with the oxidation state of the ozonation of 2-NS in terms of $\eta_{\text {TOC. }}$.

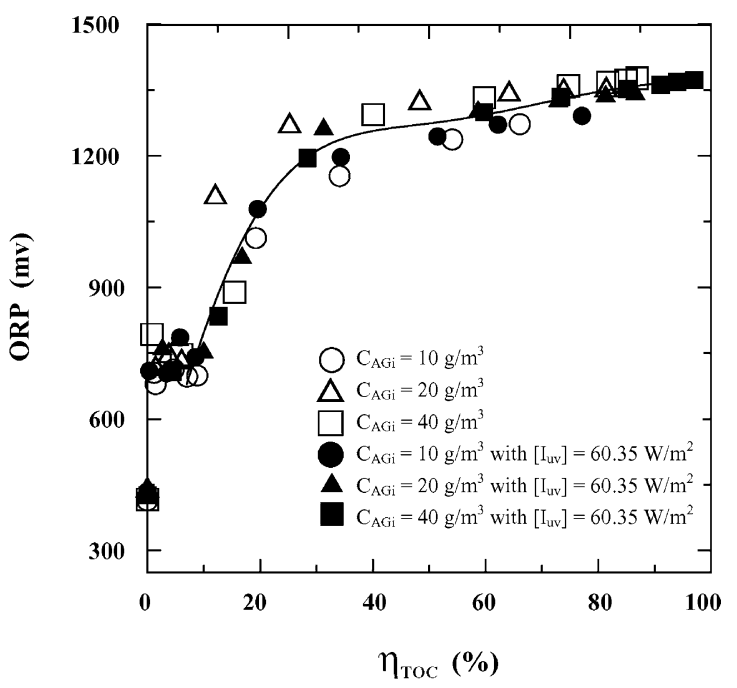

Fig. 7. ORP vs. $\eta_{\mathrm{TOC}}$ for the ozonation of 2-NS in semibatch system. Line: average and smooth curve of experimental data with $R^{2}=0.947$.
In summary, the difference in performance between $\mathrm{O}_{3}$ and $\mathrm{O}_{3} / \mathrm{UV}$ treatments regarding the destruction of 2-NS is not significant. However, the introduction of UV radiation combined with $\mathrm{O}_{3}$ gives significant contribution for the subsequent oxidation of intermediates after the disappearance of 2 -NS. The combination of ozone with UV radiation is recommended for treating the 2-NS in the electroplating solution as far as the TOC reduction is concerned, although the process with $\mathrm{O}_{3}$ alone may be sufficient for destructing the 2-NS.

\section{Conclusions}

Ozonation combined with UV radiation was employed as an effective way for the removal of 2-naphthalenesulfonate (2-NS) in the electroplating solution. The nearly complete mineralization of 2-NS can be achieved under the experimental conditions of this study. The decomposition of 2-NS accompanies the diminution of total organic carbons (TOCs) and the consumption of ozone. The following conclusions may be drawn:

1. The decomposition extent of 2-NS increases with the ozone concentration of feed gas. However, it is not significantly enhanced by the presence of UV radiation. At the time when the decomposition of 2-NS is completed, the removal efficiency of TOC ( $\left.\eta_{\text {TOC }}\right)$ is lower than $4 \%$.

2. Both the ozone concentration of feed gas and UV radiation can improve the mineralization extent of 2-NS. Limiting values of $\eta_{\mathrm{TOC}}$ of 2-NS in the electroplating solution appear for the sole ozonation of intermediates. The explanation for the phenomena can be addressed with the mechanism of ozonation of 2-NS.

3. Both the liquid- and discharged-gas ozone concentration values remain low when $\eta_{\mathrm{TOC}} \leq 34 \%$, while they increase significantly with higher $\eta_{\mathrm{TOC}}$ afterwards. Furthermore, the clear-cut relationship between $\eta_{\text {TOC }}$ and the ozone consumption was obtained in this study.

4. The oxidation reduction potential (ORP) can be used as a supplementary index of oxidation state of 2-NS in the electroplating solution. The ORP value varies with the residual TOC concentration during the ozonation of 2 NS.

\section{Acknowledgement}

This study was supported by the National Science Council of Taiwan under Grant No. NSC 89-2211-E-002-107.

\section{References}

[1] C.L. Fang, General Concepts of Additives in the Electroplating Solution, Finishing Science Pub. Co., Taipei, Taiwan, 1996.

[2] C.H. Liao, M.C. Lu, Y.H. Lin, Y.J. Chen, P.F. Hsieh, $\mathrm{H}_{2} \mathrm{O}_{2} / \mathrm{UV}$ oxidation of polyethylene glycol in copper sulfate electroplating 
wastewater of printed circuit board manufacturing, J. Chin. Inst. Environ. Eng. (Taiwan) 12 (1) (2002) 1-8.

[3] Taiwan Industrial Development Bureau (TIDB), Waste Recovery and Pollution Prevention of the Electroplating Business, Ministry of Economic Affairs of Taiwan, Taipei, Taiwan, 1997.

[4] J.L. Sotelo, F.J. Beltrán, F.J. Benítez, J. Beltrán-Heredia, Ozone decomposition in water: kinetic study, Ind. Eng. Chem. Res. 26 (1) (1987) 39-43.

[5] Y.H. Chen, C.Y. Chang, S.F. Huang, C.Y. Chiu, D. Ji, N.C. Shang, Y.H. Yu, P.C. Chiang, Y. Ku, J.N. Chen, Decomposition of 2naphthalenesulfonate in aqueous solution by ozonation with UV radiation, Water Res. 36 (16) (2002) 4144-4154.

[6] H.W. Prengle, Experimental rate constants and reactor considerations for the destruction of micropollutants and trihalomethane precursors by ozone with ultraviolet radiation, Environ. Sci. Technol. 17 (12) (1983) 743-747.

[7] R. Andreozzi, V. Caprio, R. Marotta, A. Radovnikovic, Ozonation $\mathrm{H}_{2} \mathrm{O}_{2} / \mathrm{UV}$ treatment of clofibric acid in water: a kinetic investigation, J. Hazard. Mater. B 103 (2003) 233-246.

[8] Y.H. Chen, C.Y. Chang, C.C. Chen, C.Y. Chiu, Y.H. Yu, P.C. Chiang, C.F. Chang, J.L. Shie, Kinetics of ozonation of 2-mercaptothiazoline in electroplating solution, Ind. Eng. Chem. Res. 43 (22) (2004) 6935-6942.

[9] W.L. McCabe, J.C. Smith, P. Harriott, Unit Operations of Chemical Engineering, 5th ed., McGraw-Hill, NY, USA, 1993.

[10] H. Li, C.Y. Chang, C.Y. Chiu, Y.H. Yu, P.C. Chiang, Y.H. Chen, S.J. Lee, Y. Ku, J.N. Chen, Kinetics of ozonation of polyethylene glycol in printed wiring board electroplating solution, J. Chin. Inst. Environ. Eng. (Taiwan) 10 (1) (2000) 69-75.

[11] C.Y. Chang, Y.H. Chen, H. Li, C.Y. Chiu, Y.H. Yu, P.C. Chiang, Y. $\mathrm{Ku}$, J.N. Chen, Kinetics of decomposition of polyethylene glycol in electroplating solution by ozonation with UV radiation, J. Environ. Eng. 127 (10) (2001) 908-915.

[12] F.J. Benitez, J. Beltran-Heredia, J.L. Acero, T. Gonzalez, Degradation of protocatechuic acid by two advanced oxidation processes: ozone/UV radiation and $\mathrm{H}_{2} \mathrm{O}_{2} / \mathrm{UV}$ radiation, Water Res. 30 (7) (1996) 1597-1604.

[13] I.A. Balcioğlu, N. Getoff, Advanced oxidation of 4chlorobenzaldehyde in water by UV-light, ozonation and combination of both methods, Chemosphere 39 (9) (1998) 1993-2005.

[14] B. Legube, S. Guyon, H. Sugimitsu, M. Dore, Ozonation of naphthalene in aqueous solution. 1. Ozone consumption and ozonation products, Water Res. 20 (2) (1986) 197-208.

[15] P. Berger, N.K. Vel Leitner, M. Dore, B. Legube, Ozone and hydroxyl radicals induced oxidation of glycine, Water Res. 33 (2) (1999) 433-441.

[16] S.H. Lin, S.J. Ho, Catalytic wet-air oxidation of high strength industrial wastewater, Appl. Catal. B: Environ. 9 (1996) 133-147.

[17] Y.Z. Pi, M. Ernst, J.C. Schrotter, Effect of phosphate buffer upon $\mathrm{CuO} / \mathrm{Al}_{2} \mathrm{O}_{3}$ and $\mathrm{Cu}(\mathrm{II})$ catalyzed ozonation of oxalic acid solution, Ozone Sci. Eng. 25 (2003) 393-397.

[18] C.P. Yu, Y.H. Yu, Identifying useful real-time control parameters in ozonation process, Water Sci. Technol. 42 (3-4) (2000) 435-440. 